\title{
Effects of worn and new footwear on plantar pressure in people with gout
}

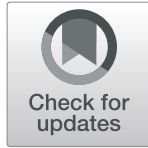

Mike Frecklington ${ }^{*}$, Nicola Dalbeth ${ }^{2,3}$, Peter McNair ${ }^{1}$, Alain Vandal ${ }^{4,5}$, Peter Gow ${ }^{6}$ and Keith Rome ${ }^{1}$

\begin{abstract}
Background: In clinical trials, good quality athletic shoes offer short-term improvements (two-months) in foot pain and disability in people with gout, but these improvements are not sustained over time. This may be due to wear and subsequent changes to the structural integrity of the shoe. The aim of this study was to examine the effects of wear on plantar pressures and footwear characteristics in shoes over six-months in people with gout.

Methods: Forty people with gout participated in a cross-sectional repeated measures study. Participants wore a pair of commercially available athletic footwear for six-months. Participants then attended a study visit where the worn footwear was compared with a new pair of the same model and size of footwear. Wear characteristics (upper, midsole, outsole) and plantar pressure were measured in the two footwear conditions. Wear characteristics were analysed using paired t-tests and Fisher's exact tests. Plantar pressure data were analysed using linear mixed models.
\end{abstract}

Results: Increases in medial midsole $(P<0.001)$, lateral midsole $(P<0.001)$ and heel midsole $(P<0.001)$ hardness were observed in the worn shoes. Normal upper wear patterns $(P<0.001)$ and outsole wear patterns $(P<0.001)$ were observed in most of the worn shoes. No differences in peak plantar pressures $(P<0.007)$ were observed between the two footwear conditions. Reduced pressure time integrals at the first metatarsophalangeal joint $(P<$ $0.001)$, second metatarsophalangeal joint $(P<0.001)$ and hallux $(P=0.003)$ were seen in the worn shoes.

Conclusions: The study found signs of wear were observed at the upper, midsole and outsole in the worn footwear after six-months. These changes to the structural properties of the footwear may affect forefoot loading patterns in people with gout.

Keywords: Gout, Footwear, Plantar pressure

\section{Background}

People with gout experience high levels of foot pain, impairment and disability [1]. A large proportion of people with gout wear inappropriate footwear that is worn, lacks cushioning and support, which is associated with pain and disability [2]. Footwear containing cushioning and support has been found to improve foot pain, impairment and disability over an eight-week period in people with gout, with no changes observed in those

\footnotetext{
* Correspondence: mike.frecklington@aut.ac.nz

${ }^{1}$ Health and Rehabilitation Research Institute, AUT University, Private Bag 92006, Auckland 1142, New Zealand

Full list of author information is available at the end of the article
}

wearing footwear lacking these features [3]. These improvements in patient reported outcomes may be attributed to the characteristics of the footwear influencing loading patterns [4].

People with gout have altered loading patterns during walking when shod $[4,5]$ and barefoot $[6]$. When wearing their own footwear, people with gout display reduced peak plantar pressures and pressure time integrals at the hallux and increased pressure time integrals at the midfoot compared to controls [5]. In people with gout, footwear characteristics that included dual density midsole, heel and forefoot cushioning and a rocker-sole reduced peak plantar pressures and pressure time integrals at the

(c) The Author(s). 2021 Open Access This article is licensed under a Creative Commons Attribution 4.0 International License, which permits use, sharing, adaptation, distribution and reproduction in any medium or format, as long as you give appropriate credit to the original author(s) and the source, provide a link to the Creative Commons licence, and indicate if changes were made. The images or other third party material in this article are included in the article's Creative Commons licence, unless indicated otherwise in a credit line to the material. If material is not included in the article's Creative Commons licence and your intended use is not permitted by statutory regulation or exceeds the permitted use, you will need to obtain permission directly from the copyright holder. To view a copy of this licence, visit http://creativecommons.org/licenses/by/4.0/ The Creative Commons Public Domain Dedication waiver (http://creativecommons.org/publicdomain/zero/1.0/) applies to the data made available in this article, unless otherwise stated in a credit line to the data. 
third and fifth metatarsals and heel, and increased pressure time integrals at the midfoot, compared to the participant's own footwear [4]. Postulated factors contributing to first metatarsophalangeal joint involvement in gout include lower temperatures, trauma, biomechanical loading and the co-existence of osteoarthritis [7]. Therefore, these changes in pressure may reflect a pain avoidance strategy where people with gout offload painful regions of the feet [5].

Although previous work has found short-term benefits in pain and disability with footwear [3], a recent clinical trial found that these were not sustained over a six-month period [8]. In this trial, participants with gout were randomised to receive either podiatric care and gout education (control group) or podiatric care, gout education and commercially available athletic footwear (footwear intervention group). Betweengroup improvements in pain, impairment and disability were seen at two-months with the footwear intervention, however, these were not observed at sixmonths. This may be due to wear and subsequent changes to the structural integrity of the footwear resulting in changes in plantar loading. The aim of this study was to examine the effects of six-months of wear on plantar pressure and footwear characteristics in people with gout.

\section{Methods}

\section{Participants}

A cross-sectional repeated measures study was undertaken. Participants with gout were recruited through newspaper advertising and from rheumatology clinics in Auckland, New Zealand. Inclusion criteria were: gout according to the 1977 preliminary American Rheumatism Association classification criteria [9] and over 20 years of age. Exclusion criteria were: history of other inflammatory arthritis, history of neuromuscular disease, experiencing a gout flare at time of assessment, medication for foot pain in the past month, history of foot or ankle surgery, or unable to walk $10 \mathrm{~m}$ unaided. Participants were fitted with a new pair ASICS Cardio Zip 3 footwear. The appropriate footwear size was determined using a Brannock device and then fitted by a podiatrist [MF]. All participants wore footwear for six-months, with self-reported diaries used to record the number of hours the footwear was worn per week. These diaries have been used in previous gout studies [3]. Participants then returned for a study visit in which they were tested with the worn shoes and a new pair of the same model of shoes. Ethical approval was obtained from the Auckland University of Technology Ethic Committee (AUTEC 14/233). All participants provided written consent.

\section{Interventions}

Two footwear conditions were evaluated; (1) a pair of commercially available athletic footwear that had been worn for 6 months (worn footwear) and; (2) a new pair of the same model of footwear (new footwear). This footwear was chosen based on the findings of a previous feasibility study [3], and its characteristics including heel/forefoot cushioning, dual density midsole, widefitting option and a zip for ease of fit. The footwear tested was the same size and model for both footwear conditions. For participants with existing foot orthoses, the sock-liner of the footwear was removed and replaced by the orthoses for testing.

\section{Procedure}

All assessments were undertaken by a single researcher [MF]. Assessments took place six-months after the initial footwear fitting, except for the assessment of the new footwear that took place prior. Worn and new footwear were assessed using the Footwear Assessment Tool [10]. Heel height and forefoot height $(\mathrm{mm})$ were both measured using digital callipers. Heel height was the average of heights measured at the medial and lateral heel. Forefoot height was the average of heights measured at the level of the first and fifth metatarsals. Heel counter stiffness, midfoot sagittal stability and midfoot torsional stability were categorised as either minimal $\left(>45^{\circ}\right)$, moderate $\left(<45^{\circ}\right)$ or rigid $\left(<10^{\circ}\right)$. Heel counter stiffness was determined by applying a force to the posterior aspect of the heel counter. Midfoot sagittal stability was determined by bending the shoe at the midfoot in sagittal plane. Midfoot frontal stability was determined by twisting the shoe in the frontal plane at the midfoot. Midsole hardness was measured using a Shore A durometer. Lateral midsole hardness was measured at the lateral midsole at the level of the heel. Medial midsole hardness was measured at the medial midsole at the level of the heel. Heel sole hardness was measured at the inferior aspect of the heel inside the shoe. Upper wear was categorised as either neutral, medial tilt (greater than $10^{\circ}$ ), or lateral tilt (greater than $10^{\circ}$ ). Midsole wear was categorised as either neutral, medial midsole compression or lateral midsole compression. Tread pattern was categorised as either no wear, partly worn or fully worn. Outsole wear was categories as either neutral (wear from lateral heel to medial forefoot), medial (greater medial wear at the heel/forefoot), or lateral (greater lateral wear at the heel/forefoot).

The following clinical characteristics were collected on the day of the assessment visit; age, gender, ethnicity, body mass index (BMI), foot posture index, history of diabetes, cardiovascular disease and peripheral vascular disease, latest serum urate, disease duration, number of gout flares in previous 3 months, presence of 
subcutaneous tophus, presence of foot subcutaneous tophus and current pharmacological management.

Prior to randomisation of the footwear conditions to be tested (new and worn footwear), participants were instructed to walk across the GAITRite walkway (CIR Systems, Inc., New Jersey, US) at a self-selected speed to determine the participant's normal walking speed [11]. GAITRite is a $700 \mathrm{~cm} \times 90 \mathrm{~cm}$ electronic walkway with an active sensor area of $609.6 \mathrm{~cm}$ long and $60.96 \mathrm{~cm}$ wide. The active area contains sensor pads (23,040 pressure activated sensors), with a spatial resolution of 1.27 $\mathrm{cm}$ and a sampling rate of $120 \mathrm{~Hz}$. The average of three trials was used to determine the participant's normal walking speed [6].

Testing order of the footwear conditions was randomised using unstratified block randomisation. The primary outcome was plantar pressure (peak plantar pressure and pressure time integrals), measured using the F-Scan ${ }^{\circ}$ Mobile system (Tekscan Inc., South Boston, MA, USA). Each insole contains 954 sensors (3.9 sensors per $1 \mathrm{~cm}^{2}$ ) and was placed on top of the sockliner. The system was calibrated prior to data acquisition [12], with data obtained using the five-stride protocol $[4,5]$. Three trials were completed in both pairs of footwear with seated breaks between trials. Walking speed was monitored during each trial using the GAITRite walkway. Following each trial, if the walking speed was $5 \%$ outside of the average self-selected speed determined prior, participants were asked to repeat the trial [13]. The FScan ${ }^{\circ}$ software package (Tekscan Inc., Version 5.24) was used to analyse the plantar pressure data (five steps per foot side). The foot was manually masked into 7 regions (heel, midfoot, first metatarsal (1MTP), second metatarsal (2MTP), lesser metatarsals (345MTP), hallux and lesser digits), mean peak plantar pressure $(\mathrm{kPa})$ and pressure time integrals $\left(\mathrm{kPa}^{*} \mathrm{sec}\right)$ were calculated. These measures have been found to be reliable in the gout population [5].

\section{Sample size calculation}

The sample size assessment is based on a previous plantar pressure study of gout and footwear [4]. In this study, the participant's own shoes and the intervention footwear were worn on the same visit and plantar pressure measurements taken under both conditions. Plantar pressure was remeasured at 8 weeks with the intervention footwear that had been in use during this period (unpublished data). The standard deviation of the differences was $152 \mathrm{kPa}$. A sample size of 40 allows the detection of a difference of $69 \mathrm{kPa}$ (effect size 0.45) between new and worn intervention footwear with $80 \%$ power at a significance level of $5 \%$ using a paired t-test. The use of a linear mixed model on repeated measures makes this power assessment conservative.

\section{Statistical analysis}

Linear mixed models were used to determine differences between plantar pressure and walking velocity and the two footwear conditions: worn footwear and new footwear. The two footwear conditions were entered as fixed effects, with the paired-foot data (left side and right side) and variables measured entered as random effects [14]. These models account for repeated measures taken from the left and right feet. Walking velocity was not paired for foot side. Paired $t$-tests and Fisher's exact tests were used to test for statistical differences in the categories of the footwear assessment form. No adjustments for covariates were made as participants acted as their own control. Significance at the 0.05 level was declared accounting for a Bonferroni correction based on the 7 plantar pressure outcomes $(P<0.007)$ and 12 footwear outcomes $(P<0.004)$. All tests were carried out against two-sided alternatives. Data were analysed using SAS/ STAT $^{\mathrm{mm}}$ software version 9.4.

Table 1 Demographic and clinical characteristics

\begin{tabular}{|c|c|}
\hline Variable & Summary \\
\hline Sex (male), n (\%) & $35(88 \%)$ \\
\hline Age (years), mean (SD) & $67(13)$ \\
\hline BMI $\left(\mathrm{kg} / \mathrm{m}^{2}\right)$, mean $(\mathrm{SD})$ & $30.5(6.5)$ \\
\hline Foot posture index, mean (SD) & $4(4)$ \\
\hline \multicolumn{2}{|l|}{ Ethnicity, n (\%) } \\
\hline European & $30(75 \%)$ \\
\hline Pacific peoples & $4(10 \%)$ \\
\hline Māori & $3(8 \%)$ \\
\hline Asian & $3(8 \%)$ \\
\hline \multicolumn{2}{|l|}{ Gout history } \\
\hline Disease duration (years), mean (SD) & $13(12)$ \\
\hline Self-reported flares in previous 3 months, mean (SD) & $0.4(0.8)$ \\
\hline Foot tophus, n (\%) & $12(30 \%)$ \\
\hline Any tophus, $n(\%)$ & $15(35 \%)$ \\
\hline Serum urate, mmol/L, mean (SD) & $0.34(0.11)$ \\
\hline \multicolumn{2}{|l|}{ Medications, n (\%) } \\
\hline Urate lowering therapy & $25(63 \%)$ \\
\hline Colchicine & $8(20 \%)$ \\
\hline Prednisone & $8(20 \%)$ \\
\hline NSAID & $14(35 \%)$ \\
\hline Diuretic & $6(15 \%)$ \\
\hline \multicolumn{2}{|l|}{ Medical history, n (\%) } \\
\hline Hypertension & $21(53 \%)$ \\
\hline Cardiovascular disease & $12(30 \%)$ \\
\hline Diabetes & $4(10 \%)$ \\
\hline Peripheral vascular disease & $3(8 \%)$ \\
\hline
\end{tabular}

BMI Body mass index, NSAID Non-steroidal anti-inflammatory drug 


\section{Results}

\section{Study participants}

A total of 40 people with gout participated in the study. The majority of participants were European with a mean (SD) age of 67 (13) years and disease duration of 13 (12) years (Table 1). The mean (SD) BMI was 30.5 (6.5) kg/ $\mathrm{m}^{2}$. Over the six-months, footwear diaries were completed in 2 month intervals, with 21 participants returning all completed diaries, 13 participants returning at least 1 completed diary and 6 participants did not complete any footwear diaries. Due to missing data, hours worn were not included in the models. For those participants who returned at least one diary, the mean (SD) duration of wearing the footwear was 20 (15) hours per week. One participant withdrew during testing due to discomfort meaning there was missing data for plantar pressure in the worn footwear.

\section{Footwear characteristics}

Reductions in heel height by $3 \%(P<0.001)$, forefoot height by $5 \%(P<0.001)$, heel counter stiffness $(P<$ $0.001)$, midfoot sagittal stiffness $(P<0.001)$ and midfoot

Table 2 Footwear characteristics

\begin{tabular}{|c|c|c|c|c|}
\hline Characteristic $^{\mathrm{a}}$ & New Shoe & Worn Shoe & $P$ & $\%$ change \\
\hline Heel height (mm), mean (SD) & $37.3(0.9)$ & $36.2(1.2)$ & $<0.001$ & $3 \%$ \\
\hline Forefoot height (mm), mean (SD) & $20.6(0.5)$ & $19.4(0.6)$ & $<0.001$ & $5 \%$ \\
\hline Heel counter stiffness, n (\%) & & & $<0.001$ & NA \\
\hline Minimal $\left(>45^{\circ}\right)$ & $0(0 \%)$ & $1(3 \%)$ & & \\
\hline Moderate $\left(<45^{\circ}\right)$ & $0(0 \%)$ & $12(30 \%)$ & & \\
\hline Rigid $\left(<10^{\circ}\right)$ & $40(100 \%)$ & $27(68 \%)$ & & \\
\hline Midfoot sagittal stiffness, n (\%) & & & $<0.001$ & NA \\
\hline Minimal $\left(>45^{\circ}\right)$ & $0(0 \%)$ & $1(3 \%)$ & & \\
\hline Moderate $\left(<45^{\circ}\right)$ & $0(0 \%)$ & $18(45 \%)$ & & \\
\hline Rigid $\left(<10^{\circ}\right)$ & $40(100 \%)$ & $21(53 \%)$ & & \\
\hline Midfoot frontal stiffness, (n\%) & & & 0.001 & NA \\
\hline Minimal $\left(>45^{\circ}\right)$ & $0(0 \%)$ & $1(3 \%)$ & & \\
\hline Moderate $\left(<45^{\circ}\right)$ & $0(0 \%)$ & $9(23 \%)$ & & \\
\hline Rigid $\left(<10^{\circ}\right)$ & $40(100 \%)$ & $30(75 \%)$ & & \\
\hline Lateral midsole hardness (Shore A), mean SD) & $57.0(0)$ & $58.3(0.9)$ & $<0.001$ & $2 \%$ \\
\hline Medial midsole hardness (Shore A), mean (SD) & $54.0(0)$ & $56.2(1.2)$ & $<0.001$ & $4 \%$ \\
\hline Heel midsole hardness (Shore A), mean (SD) & $56.0(0)$ & $58.8(1.3)$ & $<0.001$ & $5 \%$ \\
\hline Upper wear, n (\%) & & & $<0.001$ & \\
\hline None & $40(100 \%)$ & $0(0 \%)$ & & \\
\hline Medial tilt & $0(0 \%)$ & $17(43 \%)$ & & NA \\
\hline Neutral & $0(0 \%)$ & $23(58 \%)$ & & \\
\hline Lateral tilt & $0(0 \%)$ & $0(0 \%)$ & & \\
\hline Midsole wear, n (\%) & & & 0.005 & NA \\
\hline None & $40(100 \%)$ & $0(0 \%)$ & & \\
\hline Medial & $0(0 \%)$ & $8(20 \%)$ & & \\
\hline Neutral & $0(0 \%)$ & 32 (80\%) & & \\
\hline Lateral & $0(0 \%)$ & $0(0 \%)$ & & \\
\hline Tread, n (\%) & & & $<0.001$ & NA \\
\hline Not worn & $40(100 \%)$ & $0(0 \%)$ & & \\
\hline Partly worn & $0(0 \%)$ & $40(100 \%)$ & & \\
\hline Fully worn & $0(0 \%)$ & $(0 \%)$ & & \\
\hline Outsole wear, n (\%) & & & $<0.001$ & NA \\
\hline None & $40(100 \%)$ & $0(0 \%)$ & & \\
\hline Medial & $0(0 \%)$ & $0(0 \%)$ & & \\
\hline Normal & $0(0 \%)$ & $40(100 \%)$ & & \\
\hline Lateral & $0(0 \%)$ & $0(0 \%)$ & & \\
\hline
\end{tabular}


Table 3 Peak plantar pressure $(\mathrm{kPa})$

\begin{tabular}{|c|c|c|c|c|c|c|c|}
\hline \multirow[t]{2}{*}{ Parameter } & \multirow[t]{2}{*}{ Condition } & \multirow[t]{2}{*}{ Mean (SD) } & \multirow[t]{2}{*}{ Difference } & \multicolumn{2}{|c|}{ 95\% Confidence Intervals } & \multirow[t]{2}{*}{$P$} & \multirow{2}{*}{$\begin{array}{l}\% \\
\text { change }\end{array}$} \\
\hline & & & & Lower & Upper & & \\
\hline Heel & $\begin{array}{l}\text { New } \\
\text { Worn }\end{array}$ & $\begin{array}{l}318.8(73.0) \\
323.0(86.6)\end{array}$ & -4.2 & -20.3 & 11.9 & 0.61 & $1 \%$ \\
\hline Midfoot & $\begin{array}{l}\text { New } \\
\text { Worn }\end{array}$ & $\begin{array}{l}154.2(61.2) \\
157.3(84.4)\end{array}$ & -3.1 & -19.1 & 12.9 & 0.70 & $2 \%$ \\
\hline 1MTP & $\begin{array}{l}\text { New } \\
\text { Worn }\end{array}$ & $\begin{array}{l}318.5(114.6) \\
316.8(110.2)\end{array}$ & 1.7 & -14.3 & 17.7 & 0.83 & $1 \%$ \\
\hline 2MTP & $\begin{array}{l}\text { New } \\
\text { Worn }\end{array}$ & $\begin{array}{l}316.2(88.1) \\
315.5(99.4)\end{array}$ & 0.6 & -15.4 & 16.6 & 0.94 & $0 \%$ \\
\hline 345MTP & $\begin{array}{l}\text { New } \\
\text { Worn }\end{array}$ & $\begin{array}{l}266.6(96.5) \\
275.6(105.2)\end{array}$ & -9.0 & -25.0 & 6.9 & 0.27 & $3 \%$ \\
\hline Hallux & $\begin{array}{l}\text { New } \\
\text { Worn }\end{array}$ & $\begin{array}{l}284.3(124.3) \\
277.4(137.3)\end{array}$ & 6.9 & -9.0 & 22.9 & 0.39 & $2 \%$ \\
\hline Lesser toes & $\begin{array}{l}\text { New } \\
\text { Worn }\end{array}$ & $\begin{array}{l}188.1(83.8) \\
192.2(107.4)\end{array}$ & -4.1 & -20.1 & 11.8 & 0.61 & $2 \%$ \\
\hline
\end{tabular}

frontal stiffness $(P=0.001)$ were observed in the worn footwear (Table 2). Increases in medial midsole hardness by $4 \%(P<0.001)$, lateral midsole hardness by $2 \%(P<$ $0.001)$ and heel midsole hardness by $5 \%(\mathrm{P}<0.001)$ were observed in the worn footwear. Signs of outsole wear was evident in the worn footwear, with the majority displaying normal upper $(P<0.001)$, midsole $(P=0.005)$ and outsole $(P<0.001)$ wear patterns.

\section{Plantar pressure measurements}

No significant differences in peak plantar pressure were observed across the seven regions of the foot (Table 3). However, reductions in pressure time integrals of $9 \%$ at the 1MTP $(P<0.001), 6 \%$ at the 2MTP $(P<0.001)$ and $7 \%$ at the hallux $(P=0.003)$ were observed in the worn footwear compared to the new footwear (Table 4). No significant differences in pressure time integrals were observed across the other masked regions $(P>0.007)$.

\section{Discussion}

This study is the first to report on footwear characteristics and plantar pressures in people with gout over 6 months. Our key findings show reduced pressure time integrals were observed at 1MTP, 2MTP and the hallux in the worn footwear. We also observed a reduction in heel counter and midfoot stiffness, an increase in midsole hardness, together with signs of upper, midsole and outsole wear occurred following six-months of use.

No differences were observed in peak plantar pressures between the footwear conditions in people with gout. This may be due to the normal wear patterns and the amount of degradation in the structural properties of the footwear over 6 months were not large enough to have a

Table 4 Pressure time integrals ( $\mathrm{KPa}^{*} \mathrm{~s}$ )

\begin{tabular}{|c|c|c|c|c|c|c|c|}
\hline \multirow[t]{2}{*}{ Parameter } & \multirow[t]{2}{*}{ Condition } & \multirow{2}{*}{$\begin{array}{l}\text { Mean } \\
\text { (SD) }\end{array}$} & \multirow[t]{2}{*}{ Difference } & \multicolumn{2}{|c|}{ 95\% Confidence Intervals } & \multirow[t]{2}{*}{$P$} & \multirow{2}{*}{$\begin{array}{l}\% \\
\text { change }\end{array}$} \\
\hline & & & & Lower & Upper & & \\
\hline Heel & $\begin{array}{l}\text { New } \\
\text { Worn }\end{array}$ & $\begin{array}{l}43.8(10.5) \\
44.1(11.4)\end{array}$ & -0.3 & -1.5 & 0.9 & 0.60 & $1 \%$ \\
\hline Midfoot & $\begin{array}{l}\text { New } \\
\text { Worn }\end{array}$ & $\begin{array}{l}32.5(11.6) \\
32.7(12.5)\end{array}$ & -0.2 & -1.4 & 1 & 0.75 & $1 \%$ \\
\hline $1 \mathrm{MTP}$ & $\begin{array}{l}\text { New } \\
\text { Worn }\end{array}$ & $\begin{array}{l}50.9(20.1) \\
46.7(15.7)\end{array}$ & 4.2 & 3.0 & 5.3 & $<0.001$ & $9 \%$ \\
\hline 2MTP & $\begin{array}{l}\text { New } \\
\text { Worn }\end{array}$ & $\begin{array}{l}48.9(15.3) \\
46.3(13.9)\end{array}$ & 2.6 & 1.4 & 3.7 & $<0.001$ & $6 \%$ \\
\hline 345MTP & $\begin{array}{l}\text { New } \\
\text { Worn }\end{array}$ & $\begin{array}{l}45.9(16.4) \\
45.1(16.3)\end{array}$ & 0.8 & -0.4 & 2.0 & 0.18 & $2 \%$ \\
\hline Hallux & $\begin{array}{l}\text { New } \\
\text { Worn }\end{array}$ & $\begin{array}{l}31.6(13.5) \\
29.5(12.5)\end{array}$ & 2.2 & 1.0 & 3.3 & 0.003 & $7 \%$ \\
\hline Lesser toes & $\begin{array}{l}\text { New } \\
\text { Worn }\end{array}$ & $\begin{array}{l}25.2(10.9) \\
24.0(12.7)\end{array}$ & 1.2 & -0.02 & 2.3 & 0.05 & $5 \%$ \\
\hline
\end{tabular}


significant impact on peak plantar pressures. Increases in peak plantar pressure have been reported in older adults when comparing footwear with hard midsoles to soft midsoles [15], however, the differences in hardness between the footwear conditions in this study was $5 \%$ or less. Previous work has reported that people with gout frequently wear shoes that are of poor-quality and over 12 months old [2]. The footwear used in this study was constructed of materials that may be more resistant to wear compared to poor-quality footwear. The small wear patterns observed may also reflect a wearing-in period where the footwear becomes comfortable over time. In our clinical trial, improvements in footwear comfort and fit were observed over a six-month period whilst wearing the footwear evaluated in this study [8]. This suggests that good-quality footwear made of materials that offer cushioning and support are important for people with gout.

Reduced pressure time integrals at the hallux, 1MTP and 2MTP were observed in the worn footwear condition, which may be due to an immediate adaption to the new footwear at the study visit. Previous work in gout comparing new footwear with cushioning and a dual density midsole to the participants own worn footwear, reported a similar $6 \%$ reduction in pressure time integrals at the hallux in the worn footwear [4]. As patient reported outcomes were not collected as part of these studies it is unclear as to the impact these changes have on clinical outcomes. The reductions in pressure time integrals at these regions are also consistent with patterns previously reported in people with gout compared to controls when wearing worn footwear [5]. This lends further support to people with gout having reduced pressure time integrals under the hallux when walking in their own, worn footwear, which may be a painavoidance mechanism [5] or an adopted strategy [6, 11] to prevent triggering a flare [16]. The changes in loading observed in the worn footwear condition suggest a return to these abnormal gait patterns following wear over time in people with gout. Reductions in plantar pressure with rocker-sole footwear compared to the participant's own footwear have been reported in first metatarsophalangeal joint osteoarthritis as a mechanism to improve patient outcomes [17]. The current knowledge about plantar pressures and clinical efficacy in gout is unknown and we can only speculate based upon current findings. Future work could look to explore the relationship between plantar pressures and clinical outcomes in gout.

The number of hours that the footwear was worn by participants was less than what has been reported in previous gout studies $[3,8]$. This may be due to several reasons. People with gout have reported that footwear use is limited by flares, the appearance of the shoe and the different requirements of workplace and social settings [18]. The study was also conducted over a year, with seasonal differences known to affect footwear selection those with gout [19]. No minimum wear time was also prescribed to participants which may also have influenced footwear use. The adherence rates for diary completion suggest that future work should consider other strategies such as sensors [20] to record wear time.

This study has limitations. The footwear used in the study was high cost due to the quality of the shoe with its dual density midsole, heel and forefoot cushioning and a rocker profile. Our findings may not be translatable to other types of footwear, such as non-athletic footwear, or lower cost shoes with different material properties. The potential changes to the structural properties of the footwear, in the upper, midsole and outsole over a longer-period of time are not known, nor their influence on footwear comfort. Whether the observed changes to pressure time integrals translate into patientcentred outcomes such as foot pain and footwear comfort in people with gout is unknown. The diaries used to record footwear use are self-reported, did not record specific activities undertaken whilst wearing the footwear and may be subject to bias. The footwear fitting and data collection were undertaken by the same researcher, with researchers and participants unable to be blinded to the footwear conditions tested; however, bias was reduced by using a standardised protocol for assessments.

\section{Conclusion}

In conclusion, there were reductions in heel and forefoot height, increases in midsole hardness and normal upper and outsole wear patterns following six-months of footwear use. These changes in the mechanical properties of the footwear may impact foot function, as observed by alterations in forefoot loading patterns between new and worn footwear.

\section{Abbreviations \\ BMI: Body mass index; 1MTP: First metatarsal; 345MTP: Lesser metatarsals; NSAID: Non-steroidal anti-inflammatory drug; 2MTP: Second metatarsal \\ Acknowledgements \\ Not applicable. \\ Authors' contributions \\ All authors (MF, ND, PM, AV, PG, KR) made substantial contributions to conception and design of the study, MF undertook all data collection, all authors contributed to analysis and interpretation of data and to writing the manuscript. All authors were involved in drafting of the manuscript or revising it critically for important intellectual content. All authors read and approved the final manuscript.}

\section{Funding}

This study was supported, in part, by the Auckland Medical Research Foundation (5114003). 


\section{Availability of data and materials}

Data and material available for this study would require further approval upon request from the corresponding author.

\section{Declarations}

\section{Ethics approval and consent to participate}

The study complied with the Declaration of Helsinki. The study was approved by the Auckland University of Technology Ethics Committee (reference number: 14/233). All participants provided written informed consent prior to their participation in the study.

\section{Consent for publication}

Not applicable.

\section{Competing interests}

N. Dalbeth reports research grant funding from Amgen and AstraZeneca, speaker fees from Pfizer, Horizon, Janssen, and Abbvie, and consulting fees from AstraZeneca, Horizon, Dyve, and Hengrui, outside the submitted work. $K$. Rome has received funding from ASICS, outside the submitted work. ASIC $\mathrm{S}$ had no role in this study. The footwear used in the study was purchased at retail price. The other authors declare no competing interests.

\section{Author details}

'Health and Rehabilitation Research Institute, AUT University, Private Bag 92006, Auckland 1142, New Zealand. ${ }^{2}$ The University of Auckland, Private Bag 92019, Auckland 1142, New Zealand. ${ }^{3}$ Auckland District Health Board, P.O. Box 92189, Auckland, New Zealand. ${ }^{4}$ Department of Biostatistics \& Epidemiology, Auckland University of Technology, Private Bag 92006, Auckland 1142, New Zealand. ${ }^{5}$ Research \& Evaluation Office, Ko Awatea, Counties Manukau Health, Private Bag 93311, Auckland 1640, New Zealand. ${ }^{6}$ Counties Manukau District Health Board, Private Bag 94052, Auckland 2240, New Zealand.

Received: 21 January 2021 Accepted: 29 April 2021

Published online: 24 May 2021

\section{References}

1. Rome K, Frecklington M, McNair P, Gow P, Dalbeth N. Foot pain, impairment, and disability in patients with acute gout flares: a prospective observational study. Arthritis Care Res (Hoboken). 2012;64(3):384-8.

2. Rome K, Frecklington M, McNair P, Gow P, Dalbeth N. Footwear characteristics and factors influencing footwear choice in patients with gout. Arthritis Care Res (Hoboken). 2011:63(11):1599-604.

3. Rome K, Stewart S, Vandal AC, Gow P, McNair P, Dalbeth N. The effects of commercially available footwear on foot pain and disability in people with gout: a pilot study. BMC Musculoskelet Disord. 2013;14:278.

4. Stewart S, Dalbeth N, McNair P, Parmar P, Gow P, Rome K. The effect of good and poor walking shoe characteristics on plantar pressure and gait in people with gout. Clin Biomech (Bristol, Avon). 2014;29(10):1158-63.

5. Rome K, Survepalli D, Sanders A, Lobo M, McQueen FM, McNair P, et al. Functional and biomechanical characteristics of foot disease in chronic gout: a case-control study. Clin Biomech (Bristol, Avon). 2011;26(1):90-4.

6. Stewart S, Dalbeth N, Vandal AC, Rome K. Spatiotemporal gait parameters and plantar pressure distribution during barefoot walking in people with gout and asymptomatic hyperuricemia: comparison with healthy individuals with normal serum urate concentrations. J Foot Ankle Res. 2016;9:15.

7. Roddy E. Revisiting the pathogenesis of podagra: why does gout target the foot? J Foot Ankle Res. 2011:4(1):13.

8. Frecklington $M$, Dalbeth $N$, McNair P, Morpeth $T$, Vandal AC, Gow P, et al. Effects of a footwear intervention on foot pain and disability in people with gout: a randomised controlled trial. Arthritis Res Ther. 2019;21(1):104.

9. Wallace SL, Robinson H, Masi AT, Decker JL, McCarty DJ, Yü T-F. Preliminary criteria for the classification of the acute arthritis of primary gout. Arthritis Rheum. 1977;20(3):895-900.

10. Barton CJ, Bonanno D, Menz HB. Development and evaluation of a tool for the assessment of footwear characteristics. J Foot Ankle Res. 2009;2:10.

11. Stewart S, Morpeth T, Dalbeth N, Vandal AC, Carroll M, Davidtz L, et al. Footrelated pain and disability and spatiotemporal parameters of gait during self-selected and fast walking speeds in people with gout: a two-arm cross sectional study. Gait Posture. 2016;44:18-22.
12. Rome K, Survepalli DG, Lobo M, Dalbeth N, McQueen FM, McNair P. Evaluating intratester reliability of manual masking of plantar pressure measurements associated with chronic gout. J Am Podiatr Med Assoc. 2011 101(5):424-9.

13. Burnfield JM, Few CD, Mohamed OS, Perry J. The influence of walking speed and footwear on plantar pressures in older adults. Clin Biomech (Bristol, Avon). 2004;19(1):78-84.

14. Stewart S, Pearson J, Rome K, Dalbeth N, Vandal AC. Analysis of data collected from right and left limbs: accounting for dependence and improving statistical efficiency in musculoskeletal research. Gait Posture. 2018:59:182-7.

15. Lane TJ, Landorf KB, Bonanno DR, Raspovic A, Menz HB. Effects of shoe sole hardness on plantar pressure and comfort in older people with forefoot pain. Gait Posture. 2014;39(1):247-51.

16. ten Klooster PM, Vonkeman HE, Oude Voshaar MAH, Bode C, van de Laar MAFJ. Experiences of gout-related disability from the patients' perspective: a mixed methods study. Clin Rheumatol. 2014;33(8):1145-54.

17. Menz HB, Auhl M, Tan JM, Levinger P, Roddy E, Munteanu SE. Biomechanical effects of prefabricated foot orthoses and rocker-sole footwear in individuals with first metatarsophalangeal joint osteoarthritis. Arthritis Care Res (Hoboken). 2016;68(5):603-11.

18. Frecklington M, Williams A, Dalbeth N, McNair P, Gow P, Rome K. The footwear experiences of people with gout: a qualitative study. J Foot Ankle Res. 2019;12:38.

19. Brenton-Rule A, Hendry GJ, Barr G, Rome K. An evaluation of seasonal variations in footwear worn by adults with inflammatory arthritis: a crosssectional observational study using a web-based survey. J Foot Ankle Res. 2014;7:36.

20. Menz HB, Bonanno DR. Objective measurement of adherence to wearing foot orthoses using an embedded temperature sensor. Med Eng Phys. 2021; 88:19-24.

\section{Publisher's Note}

Springer Nature remains neutral with regard to jurisdictional claims in published maps and institutional affiliations.
Ready to submit your research? Choose BMC and benefit from:

- fast, convenient online submission

- thorough peer review by experienced researchers in your field

- rapid publication on acceptance

- support for research data, including large and complex data types

- gold Open Access which fosters wider collaboration and increased citations

- maximum visibility for your research: over $100 \mathrm{M}$ website views per year

At BMC, research is always in progress.

Learn more biomedcentral.com/submissions 